\title{
CÁTEDRAS UNESCO. CONSERVACIÓN DEL PATRIMONIO CULTURAL Y DESARROLLO SOSTENIBLE
}

\author{
UNESCO CHAIRS. CONSERVATION OF THE CULTURAL HERITAGE \\ AND SUSTAINABLE DEVELOPMENT
}

\author{
Sara Beatriz Guardia \\ Universidad de San Martín de Porres, Perú
}

\section{RESUMEN}

El patrimonio cultural es un legado histórico que requiere ser cuidado y preservado por su creatividad, diversidad cultural, y porque es un factor identitario. Desde esta perspectiva, la relación entre las Cátedras UNESCO y la conservación patrimonial es sustancial. Se analiza su correspondencia a partir del marco estatutario de protección aprobado por la UNESCO en 1972, y la adopción del concepto de Valor Universal Excepcional (VUE) del Patrimonio Mundial. Así como las siguientes convenciones, el Plan de Trabajo de Cultura de la UNESCO para América Latina, la función de la Cultura, la Educación y de las Cátedras UNESCO. Y, de manera particular, el Patrimonio Cultural del Perú y sus doce bienes y sitios culturales inscritos en la Lista del Patrimonio Mundial de la UNESCO. En este contexto, la Cátedra UNESCO Patrimonio Cultural y Turismo Sostenible de la Universidad de San Martín de Porres (USMP), contribuye al desarrollo sostenible desde la universidad, en los ámbitos locales, regionales y nacionales.

Palabras clave: Patrimonio Cultural, Desarrollo sostenible, Convenciones UNESCO, Cátedras UNESCO, Cultura, Educación, Patrimonio Cultural del Perú.

\begin{abstract}
Cultural heritage is a historical legacy that needs to be taken care of and preserved for its creativity, cultural diversity, and because it is an identity factor. From this perspective, the relationship between UNESCO Chairs and heritage conservation is substantial. Their correspondence is analyzed based on the statutory framework of protection approved by UNESCO in 1972, and the adoption of the concept of Outstanding Universal Value (OUV) of the World Heritage. As well as the following conventions, the UNESCO Culture Work Plan for Latin
\end{abstract}

Este es un artículo Open Access bajo la licencia Creative Commons AtribuciónNoComercial-Compartirlgual 4.0

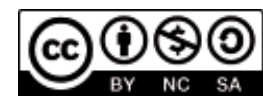


America, the role of Culture, Education and the UNESCO Chairs. And, in particular, the Cultural Heritage of Peru and its twelve cultural assets and sites inscribed on the UNESCO World Heritage List. In this context, the UNESCO Chair Cultural Heritage and Sustainable Tourism of the USMP, contributes to sustainable development from the university, at local, regional and national levels.

Keywords: Cultural Heritage, Sustainable development, UNESCO Conventions, UNESCO Chairs, Culture, Education, Cultural Heritage of Peru.

El patrimonio cultural es un legado histórico que requiere ser cuidado y preservado. Según la UNESCO, “es la gama completa de nuestras tradiciones, monumentos, objetos y cultura heredados. Y si bien la investigación y el estudio humanístico del pasado es y seguirá siendo la base de las actividades patrimoniales, está surgiendo un cambio en una visión más integral del patrimonio que se refleja en la interpretación del mismo” (como se citó en DeBrine, 2016). Contribuye a la creatividad, la revalorización, y el acceso a la diversidad cultural. Es también un factor identitario.

Desde esta perspectiva, la UNESCO propuso un marco estatutario de protección y salvaguarda en la Conferencia General realizada en París del 17 de octubre al 21 de noviembre de 1972, cuando aprobó la Convención sobre el Patrimonio Mundial Cultural y Natural ${ }^{1}$, adoptando el concepto de Valor Universal Excepcional (VUE) del Patrimonio Mundial con el objetivo de crear conciencia, "que había patrimonios en el mundo cuya importancia era tal que los hacía valiosos para toda la humanidad, y que la responsabilidad de su gestión tenía una significación ultranacional, aunque el compromiso primordial siguiera recayendo en las naciones a título individual” (UNESCO, ICCROM, ICOMOS, \& UICN, 2014, p. 3).

Según la Convención de 1972, el Patrimonio Cultural comprende los monumentos, obras arquitectónicas, de escultura o de pintura, estructuras de carácter arqueológico, inscripciones, cavernas, construcciones, aisladas o reunidas, cuya arquitectura unida e integrada en el paisaje les brinda un Valor Universal Excepcional desde el punto de vista de la historia, del arte y la ciencia. Mientras que el Patrimonio Cultural Inmaterial está compuesto de tradiciones y expresiones orales, incluido el idioma, artes del espectáculo, rituales y actos festivos. Así como también, técnicas artesanales tradicionales, y conocimientos y usos relacionados con la naturaleza y el universo.

El Comité Intergubernamental del Patrimonio Mundial está integrado por representantes de 21 Estados Partes elegidos en la Asamblea General por un mandato de seis años. El Comité es responsable de la aplicación de la Convención y de determinar los bienes que se inscribirán en la Lista del Patrimonio Mundial basándose en las recomendaciones de dos órganos consultivos: el Consejo Internacional de Monumentos y Sitios (ICOMOS) para los sitios culturales y la Unión Mundial para la Naturaleza (UICN) para los naturales. Un tercer órgano consultivo, el Centro Internacional de Estudios de Conservación y Restauración de los Bienes Culturales, proporciona asesoría técnica en restauración de monumentos y gestión del patrimonio cultural. Organiza también cursos de capacitación para especialistas.

1 Conocida como Convención del Patrimonio Mundial. 
La Convención para la Salvaguarda del Patrimonio Cultural Inmaterial (2003) y La Convención de Protección y Promoción de la Diversidad Cultural (2005), proporcionaron un marco normativo respecto de los enfoques utilizados para comprender las distintas dimensiones del patrimonio cultural. A partir de la propuesta de Convención de 1972, según la cual la pérdida o deterioro de bienes patrimoniales que poseen un valor de carácter excepcional y universal, no solo significa una perdida para el país de origen sino también para toda la humanidad, la convención de 2003 agregó dos conceptos importantes: la característica complementaria entre el patrimonio tangible e intangible, y el papel protagónico que deben tener las comunidades portadoras en el manejo y salvaguarda de sus expresiones patrimoniales intangibles. Mientras que la convención de 2005, resaltó el valor de la diversidad cultural como un aspecto fundamental en el desarrollo de los seres humanos.

El 23 de setiembre del 2005 el Perú se convirtió en Estado Parte de la Convención asumiendo deberes, obligaciones y responsabilidades. Es decir, que las políticas públicas del Estado, empresas e instituciones y la población pasaron a ser normadas también por el derecho internacional. El Estado peruano amplió así los estándares de protección del patrimonio cultural y natural.

A lo largo de casi cincuenta años de vigencia de la Convención, la Lista del Patrimonio Mundial ha tenido un constante aumento, y se han agregado sitios patrimoniales complejos con requisitos más exigentes de gestión. También el concepto de patrimonio cultural se ha ampliado. Por ello, la Convención se aplica no solo a las grandes edificaciones y centros urbanos de todas las épocas, sino también a los vestigios igualmente significativos, aunque más frágiles de los distintos procesos que ha seguido la humanidad. Así, la Lista del Patrimonio Mundial se ha ampliado hasta incluir paisajes culturales y manifestaciones de la ciencia, la tecnología, la industria y la agricultura. Todo lo cual ha producido que también la gestión enfrente una situación mucho más compleja.

Entonces cabría preguntarse cómo conciliar la conservación del patrimonio frente a la creciente complejidad y a la amenaza de diversas causas. Al respecto, la Convención ha impartido orientaciones precisas a los Estados Partes:

El sistema del Patrimonio Mundial asigna a los Estados Partes la responsabilidad principal de los bienes, y el éxito de la gestión depende del contexto político, social, institucional y económico del bien administrado. En efecto, el cambio en el sector del patrimonio de una simple protección física a un enfoque de la gestión que tenga en cuenta problemas sociales, económicos y ambientales, atribuye al patrimonio una función en la vida colectiva, como prevé el artículo 5 de la Convención. Este enfoque más holístico ha hecho que sea aún más exigente la gestión de los bienes del Patrimonio Mundial. (De Caro, 2014, p. 4)

Según el artículo 6.1, ese patrimonio constituye un patrimonio universal en cuya protección la comunidad internacional tiene el deber de cooperar y participar en dos fases diferentes y significativas:

En primer lugar el Estado Parte debe explicar, en el marco del proceso de inscripción, cómo gestionará el Valor Universal Excepcional del bien respondiendo a las preguntas del formulario de inscripción y demostrando la existencia de un plan u otro sistema de gestión, que sea adecuado para proteger el 
bien. Después de la inscripción, el Estado Parte debe cumplir el compromiso de salvaguardar el Valor Universal Excepcional del bien mediante una gestión eficaz a largo plazo y una serie de procedimientos del Patrimonio Mundial que permitirán verificar la protección. (De Caro, 2014, pp. 4-5)

Cuando sobre un sitio pesa alguna amenaza relacionada con el cambio climático, problemas regionales, fragmentación del hábitat, caza furtiva, afluencia excesiva de visitantes o eliminación de desechos, el Comité del Patrimonio Mundial o el Estado Parte pueden solicitar una supervisión. Una vez realizada, el Comité efectúa recomendaciones destinadas a solucionar los problemas y puede recurrir cuando sea necesario a la asistencia internacional. El Comité del Patrimonio Mundial ha optado por aplicar un enfoque regional a la presentación periódica de informes como medio de promover estrategias y mecanismos de cooperación regionales.

Para coadyuvar con esta tarea la UNESCO ha publicado una colección de manuales para "brindar indicaciones concretas sobre la aplicación de la Convención a los Estados Partes, las autoridades encargadas de la protección del patrimonio, las autoridades locales, los administradores de sitios y las comunidades locales vinculadas a los sitios del Patrimonio Mundial, así como a otras partes interesadas en el proceso de reconocimiento y preservación de esos sitios. Su propósito es suministrarles información y asistencia con el fin de que la Lista de Patrimonio Mundial sea representativa y digna de crédito y los bienes inscritos sean objeto de una protección adecuada y una gestión eficaz” (UNESCO, ICCROM, ICOMOS, \& UICN, 2014).

A partir del informe sobre el estado de conservación y del asesoramiento de los Organismos Consultivos, y en consulta con los Estados Partes, el Comité puede incluir sitios en la Lista del Patrimonio Mundial en Peligro. Esta Lista se estableció en conformidad con el artículo 11.4 de la Convención del Patrimonio Mundial, para los bienes del Patrimonio Mundial amenazados por peligros cuya protección exige trabajos de conservación y de apoyo (UNESCO, 1972). El capítulo IV.B de las Directrices prácticas (UNESCO, 2012) contiene instrucciones para la inscripción de los bienes en la Lista del Patrimonio Mundial en las categorías de peligro “comprobado” o peligro “potencial”.

Por "peligro comprobado" se entiende un peligro concreto e inminente. En el caso de los bienes culturales puede ser la alteración grave de materiales o estructuras, de la coherencia arquitectónica o urbanística o de la planificación rural, y la pérdida de autenticidad histórica o cultural. El "peligro potencial” lo plantean las amenazas que puedan tener repercusiones perjudiciales en los valores de un sitio del Patrimonio Mundial. Para los bienes culturales, estos peligros pueden comprender una modificación de la condición jurídica o administrativa, la falta de una política de conservación, los peligros derivados de la planificación regional o urbana, y los cambios debido a factores geológicos o climáticos (UNESCO, ICCROM, ICOMOS, \& UICN, 2014, p. 34).

La gestión correcta del patrimonio cultural exige un enfoque que ponga énfasis en la sostenibilidad, basada en el equilibrio entre la obtención de beneficios del patrimonio cultural y su preservación para las generaciones futuras. Según los Indicadores de la Cultura para el Desarrollo, la sostenibilidad del patrimonio depende en gran medida de una acertada gestión, y de políticas y acciones que garanticen la protección del patrimonio cultural frente a los desafíos y los impactos de la globalización y la sobreexplotación. 
Los factores que sustentan la sostenibilidad del patrimonio tienen tres componentes interrelacionados: (a) Registro e inscripción, porque proporciona el grado en que se reconocen como valiosos los recursos patrimoniales de un país, y el nivel de compromiso en la elaboración de los registros y su actualización periódica porque indica el grado de prioridad que se concede al patrimonio; (b) Protección, Salvaguarda y Gestión, porque expresa la medida en que las autoridades públicas valoran y aseguran la conservación y la gestión sostenible del patrimonio; y (c) Transmisión y Movilización de Apoyos, porque muestra el esfuerzo desplegado con el objetivo de transmitir a los ciudadanos y a las comunidades el conocimiento y valor del patrimonio.

\section{Relación entre la conservación del patrimonio cultural y el desarrollo sostenible}

En los últimos años, resultado de la globalización, el crecimiento demográfico y las presiones sociales, se ha abierto una reflexión sobre la relación entre conservación y desarrollo sostenible; es decir, del equilibrio entre la satisfacción de las necesidades humanas básicas y la utilización del uso de recursos. En efecto, frente a los nuevos desafíos, el patrimonio no podía "limitarse al papel de conservación pasiva que desempeñó en el pasado”, sino que debía "proporcionar las herramientas y el marco para contribuir a configurar, delinear y dirigir el desarrollo de las sociedades del mañana” (ICOMOS, 2011, p. 9).

Así mismo, considerar a los sitios «vivos» como parte del patrimonio, y no solo como monumentos. "Estos sitios vivos del patrimonio se consideran importantes no solo por lo que nos dicen del pasado sino también por su condición de testimonios de la continuidad de las viejas tradiciones en la cultura de nuestros días, y por dar pruebas implícitas de su sostenibilidad” (UNESCO, ICCROM, ICOMOS, \& UICN, 2014, p. 20).

Así, la relación entre patrimonio cultural y desarrollo sostenible se puede enfocar desde dos perspectivas: que el patrimonio cultural expresa y refleja el pasado histórico y la diversidad cultural como parte de los recursos que deben protegerse y transmitirse a las generaciones futuras; y que el patrimonio y su conservación aportan al desarrollo social, económico y ambiental. Por lo tanto, «el sector del patrimonio, en su condición de importante agente de la sociedad y de elemento de un sistema vasto de componentes mutuamente interdependientes, debe aceptar la responsabilidad que le incumbe en el desafío global, la creciente presión de las actividades humanas, los recursos financieros y ambientales, y el cambio climático» (UNESCO, ICCROM, ICOMOS, \& UICN, 2014, pp. 21-22).

Por ello, uno de los objetivos centrales de la Convención del Patrimonio Mundial es promover la participación de las poblaciones locales en la preservación de su patrimonio natural y cultural, como está indicado en los Objetivos Estratégicos del Comité del Patrimonio Mundial, Comunicación y Comunidades (UNESCO, ICCROM, ICOMOS, \& UICN, 2014, p. 24). Con frecuencia las comunidades locales dependen de su patrimonio para su identidad cultural o para su subsistencia, y también pueden contribuir a sus valores culturales y a su gestión.

Actualmente el desarrollo sostenible es un objetivo universalmente aceptado a nivel local, nacional y mundial. Recientes estudios han proporcionado y ampliado nuevos e innovadores enfoques del concepto de sostenibilidad social, al incluir términos como: buena vida, felicidad, bienestar, que "se están introduciendo en las políticas y las estadísticas oficiales, reflejando indicadores más subjetivos y cualitativos que exclusivamente cuantitativos. 
Este principio fundamental está reconocido en los párrafos 30, 58 y 134 del documento final de Río + 20, «El futuro que queremos” (UNESCO, ICCROM, ICOMOS, \& UICN, 2014, pp. 21).

\section{UNESCO y el Plan de Trabajo de Cultura para América Latina y el Caribe 2016-2021}

Por cultura se comprende el conjunto de rasgos distintivos, espirituales y materiales, intelectuales y afectivos que caracterizan a una sociedad o un grupo social. Comprende, además, las artes y las letras, los modos de vida, los derechos fundamentales del ser humano, los sistemas de valores, las tradiciones y las creencias (MONDIACULT, 1982). Por lo tanto, la cultura es un medio de transmisión de conocimiento pasado y presente, un elemento impulsor del desarrollo sostenible, la paz y el progreso económico, que une a las sociedades y las naciones que reconocen el valor excepcional de su patrimonio construido y natural para consolidar así el sentimiento de identidad y continuidad.

Consecuentemente, el Plan de Acción para el Patrimonio Mundial de América Latina y El Caribe 20042014², identifica a la educación como factor primordial para una mejor comprensión, conservación y gestión del patrimonio cultural y natural. A la vez que contempla las Categorías de patrimonio urbano, Sitios naturales, Paisajes culturales y Patrimonio arqueológico, formulando una importante línea de acción: desarrollar estrategias de educación y divulgación en los niveles regionales, subregionales y nacionales en relación con las responsabilidades y los beneficios de la Convención del Patrimonio Mundial y los conceptos de Patrimonio Mundial Liderado por los Estados Partes, con la colaboración del Centro del Patrimonio Mundial y Organizaciones Consultivas. El Plan de Acción constituye una agenda específica que sirve para fomentar la cooperación regional y fortalecer la coordinación de esfuerzos entre los países de América Latina y el Caribe.

También le otorga valor al turismo sostenible (Pedersen, 2005), porque si bien el turismo está considerado como un importante factor de ingresos económicos, a la vez constituye una amenaza en la gestión y la conservación de los bienes del Patrimonio Mundial. Un número significativo de sitios reporta un fuerte crecimiento de visitantes sin contar con mecanismos de planificación adecuados para enfrentar este crecimiento, y el aumento de las amenazas derivadas de la deficiente infraestructura y desarrollo. No obstante, señala el Plan, en la Región se están realizando esfuerzos que aportan lecciones valiosas para responder a los desafíos y mejorar la gestión del turismo como una actividad que contribuya efectivamente al desarrollo sostenible. Los esfuerzos en este sentido refuerzan la participación local y las capacidades para que el turismo sea un factor que contribuya a la conservación de los bienes y al desarrollo sostenible de las comunidades locales, tradicionales e indígenas.

Estas acciones están integradas en el Plan de Trabajo de Cultura para América Latina y el Caribe de la UNESCO 2016-2021, comprendidas en cuatro áreas temáticas ${ }^{3}$ :

- Desarrollo de políticas y legislación nacionales para garantizar la protección y la promoción del patrimonio y sus sistemas de valores y expresiones culturales, como parte del acervo común, dándole al mismo tiempo un papel central en la vida de las sociedades.

\footnotetext{
Patrimonio Mundial. WHC-04/28.COM/16. París, 18 de mayo de 2004. Original: Inglés.

Declaración de Hangzhou, 2013.
} 
- Fortalecer y utilizar las capacidades nacionales para proteger, salvaguardar y gestionar de manera sostenible y responsable el patrimonio y la diversidad de expresiones culturales. Para lo cual, se otorgará especial atención en asistir a los Estados Miembros en la aplicación y seguimiento de los instrumentos normativos de la UNESCO, a través del fortalecimiento de las normas jurídicas e institucionales.

- Fomentar estudios científicos, técnicos y artísticos; metodologías de investigación para la protección, conservación, salvaguarda y gestión eficaz del patrimonio y la diversidad de expresiones culturales, así como, desarrollar y aplicar indicadores del impacto de la cultura en el desarrollo social y económico de las sociedades.

- Fomentar y desarrollar mecanismos de cooperación internacional para compartir el conocimiento y la información; facilitar el intercambio tecnológico; utilizar y fortalecer redes e instituciones nacionales e internacionales ya existentes, y movilizar recursos humanos y financieros.

\section{Cátedras UNESCO. La función de la cultura y la educación}

El artículo 27 de la Convención del Patrimonio Mundial señala expresamente que el objetivo de los programas de educación e información es "estimular en sus pueblos (de los Estados Partes) el respeto y aprecio al patrimonio cultural y natural definido en los artículos 1 y 2 de la presente Convención”. Desde esa perspectiva de conformidad con una resolución aprobada por la Conferencia General de UNESCO durante su 26ª reunión en 1992, se creó el Programa UNITWIN ${ }^{4}$ y Cátedras UNESCO para desarrollar y mejorar la investigación y capacitación de la educación superior a través de la cooperación interuniversitaria y la transferencia del conocimiento. Estableciendo así una red a escala internacional para la promoción de la participación, la movilidad académica y la transferencia de conocimiento.

A través de la Red UNITWIN, los centros de educación y las instituciones de investigación superior, pueden unir sus recursos materiales y humanos con el objetivo de enfrentar los desafíos y contribuir al desarrollo de las sociedades. Los proyectos son en su mayoría interdisciplinarios y participan en ellos todos los sectores del programa de la UNESCO.

Con la constitución de las Cátedras UNESCO se fomenta la cooperación y los vínculos interuniversitarios en aras de reforzar las capacidades institucionales a través del intercambio de conocimientos y la contribución en temas de interés de la UNESCO relacionados a la educación, las ciencias naturales, ciencias sociales, la cultura y la comunicación. La creación de las Cátedras UNESCO significa uno de los más importantes aportes a la promoción y difusión de la investigación académica y el conocimiento multidisciplinar.

\section{Cátedra UNESCO Patrimonio Cultural y Turismo Sostenible de la Universidad de San Martín de Porres}

En febrero de 2018, la UNESCO aprobó la creación de la Cátedra Patrimonio Cultural y Turismo Sostenible de la Universidad de San Martín de Porres, concebida para contribuir a través de la formación y especialización

\footnotetext{
$4 \quad$ UNITWIN: University Twinning and Networking (Plan de hermanamiento e interconexión de universidades).
} 
de profesionales, la investigación, la difusión y las alianzas interuniversitarias, a la puesta en valor del patrimonio cultural, material e inmaterial del Perú desde la universidad, en los ámbitos locales, regionales y nacionales. Así como, la promoción del turismo cultural sostenible y compatible con las normas y valores de las diversas convenciones de la UNESCO.

Con este objetivo, la Cátedra UNESCO Patrimonio Cultural y Turismo Sostenible de la Universidad de San Martín de Porres, ha elaborado un programa tendiente a promover el potencial educativo del patrimonio, fortaleciendo los conocimientos tradicionales e integrando el patrimonio en la enseñanza. Con esta finalidad, creará un Diplomado sobre Patrimonio Cultural y Turismo sostenible; y desarrollará programas interrelacionados: estudios de bachillerato y formación académica y profesional; organizará conferencias, mesas redondas y seminarios internacionales y firmará convenios de cooperación con gobiernos regionales y municipales.

"El Perú es un Estado y una sociedad que tienen como uno de sus más importantes y competitivos atributos y recursos, su patrimonio cultural y la biodiversidad de su medio geográfico” (Rodríguez, 2017). El patrimonio material se enriqueció en este proceso de evolución y consolidación de la cultura peruana, cuyo signo distintivo es su diversidad y pluralidad. Patrimonio que se expresa en conjuntos arqueológicos, edificaciones y centros urbanos, representativos en todos los períodos de la historia nacional.

En el transcurso de las diferentes etapas de la historia del Perú, desde las culturas preincaicas, el Imperio de los Incas, la conquista española, la lucha por la independencia y la república, las diferentes manifestaciones culturales, regionales y locales, «han creado una vasta multiplicidad de expresiones de cultura inmaterial: usos, representaciones, expresiones, conocimientos y técnicas que comprenden, entre otras, expresiones y tradiciones orales, artes del espectáculo, rituales y eventos festivos, conocimientos y prácticas relativas a la naturaleza y el universo, expresiones espirituales religiosas» (USMP, 2017).

Es por ello, que el patrimonio cultural, material e inmaterial, es también un factor identitario, en el que comunidades locales, pueblos y regiones afirman y recrean su propia historia y sus sentimientos de pertenencia y cohesión subjetiva y social.

En consecuencia, el turismo que se desarrolla en el Perú con cierta intensidad a partir de la tercera década del siglo XX, es esencialmente un turismo cultural e histórico cuyo recurso fundamental es su patrimonio natural, cultural, material e inmaterial. Actividades que corresponden a un turismo sostenible que tiene como principio básico establecer normas de uso responsable, conservando y manteniendo un adecuado equilibrio con el entorno natural y la participación y respeto por la cultura.

\section{El Patrimonio Cultural del Perú}

Los criterios de inscripción de los bienes culturales en la Lista del Patrimonio Mundial de la UNESCO, están definidos en la Declaración de Valor Universal Excepcional (VUE), que significa que su categoría cultural y/o natural trasciende las fronteras nacionales y reviste de crucial importancia para las futuras generaciones y para la humanidad. El carácter de VUE constituye un requisito obligatorio para la inscripción, por lo cual, es necesario cumplir con al menos uno de los diez criterios establecidos. Los bienes culturales están comprendidos entre los 
criterios del (i) al (vi); los bienes naturales entre los criterios del (vii) al (x). Así mismo, deben cumplir con los requisitos de autenticidad y/o integridad (UNESCO, World Heritage Centre - WHC, 2008):

(i) Representar una obra maestra del genio creador humano.

(ii) Atestiguar un intercambio de valores humanos considerable, durante un período concreto o en un área cultural del mundo determinada, en los ámbitos de la arquitectura o la tecnología, las artes monumentales, la planificación urbana o la creación de paisajes.

(iii) Aportar un testimonio único, o al menos excepcional, sobre una tradición cultural o una civilización viva o desaparecida.

(iv) Ser un ejemplo eminentemente representativo de un tipo de construcción o de conjunto arquitectónico o tecnológico, o de paisaje que ilustre uno o varios períodos significativos de la historia humana.

(v) Ser un ejemplo destacado de formas tradicionales de asentamiento humano o de utilización de la tierra o del mar, representativas de una cultura (o de varias culturas), o de interacción del hombre con el medio, sobre todo cuando este se ha vuelto vulnerable debido al impacto provocado por cambios irreversibles.

(vi) Estar directa o materialmente asociado con acontecimientos o tradiciones vivas, ideas, creencias u obras artísticas y literarias que tengan una importancia universal excepcional (el Comité considera que este criterio debería utilizarse preferentemente de modo conjunto con los otros criterios).

(vii) Representar fenómenos naturales o áreas de belleza natural e importancia estética excepcionales.

(viii) Ser ejemplos eminentemente representativos de las grandes fases de la historia de la tierra, incluido el testimonio de la vida, de procesos geológicos en curso en la evolución de las formas terrestres o de elementos geomórficos o fisiográficos significativos.

(ix) Ser ejemplos eminentemente representativos de procesos ecológicos y biológicos en curso en la evolución y el desarrollo de los ecosistemas terrestres, acuáticos, costeros y marinos; y las comunidades de vegetales y animales terrestres, acuáticos, costeros y marinos.

(x) Contener los hábitats naturales más representativos y más importantes para la conservación in situ de la diversidad biológica, comprendidos aquellos en los que sobreviven especies amenazadas que tienen un valor universal excepcional, desde el punto de vista de la ciencia o de la conservación.

Son doce los bienes y sitios culturales del Perú inscritos en la Lista del Patrimonio Mundial fundamentados en su Valor Universal Excepcional (VUE) de acuerdo con los diez criterios mencionados: Ocho de Patrimonio Cultural, dos de Patrimonio Natural y dos de Patrimonio Mixto:

1. Ciudad del Cusco Patrimonio Cultural (1983)

2. Santuario Histórico de Machu Picchu Patrimonio Mixto (1983)

3. Parque Nacional de Huascarán Patrimonio Natural (1985) 
4. Sitio Arqueológico de Chavín Patrimonio Cultural (1985)

5. Zona Arqueológica de Chan Chan Patrimonio Cultural. Lista en Peligro (1986)

6. Parque Nacional de Manu Patrimonio Natural (1987)

7. Centro Histórico de Lima Patrimonio Cultural (1988-1991)

8. Parque Nacional del Río Abiseo Patrimonio Mixto (1990-1992)

9. Líneas y Geoglifos de Nazca y Palpa Patrimonio Cultural (1994)

10. Centro Histórico de la ciudad de Arequipa Patrimonio Cultural (2000)

11. Ciudad Sagrada de Caral - Supe Patrimonio Cultural (2009)

12. Qhapaq Ñan Sistema Vial Andino Patrimonio Cultural (2014)

\section{Ciudad del Cusco Patrimonio Cultural}

Inscripción: 7ª Sesión del Comité del Patrimonio Mundial. Florencia, 9 de diciembre, 1983.

La ciudad del Cusco fue el centro urbano más importante del Imperio del Tahuantinsuyo, fundada por el Inca Manco Cápac, y conformaba de palacios, templos, canchas (viviendas); con calles y plazas, y rodeada de extensas áreas para la agricultura y artesanía. Alcanzó su mayor desarrollo con el Inca Pachacútec en el siglo XV. Cuando los españoles conquistaron el Imperio incaico en 1534, erigieron la ciudad española sobre los recintos y construcciones inca (Centro del Patrimonio Mundial, 2013). La ciudad del Cusco ha sido reconocida como patrimonio cultural por su excepcional valor universal al representar una obra maestra del genio creador humano (Criterio i). Constituye un testimonio único del Imperio del Tahuantinsuyo, que ejerció control político, religioso y administrativo en varios países de América del Sur entre los siglos XV y XVI. La ciudad representa 3000 años de desarrollo cultural indígena y autónomo en los Andes del sur del Perú (Criterio iii). Así mismo, la ciudad del Cusco ofrece un testimonio único de los logros urbanos y arquitectónicos de asentamientos políticos, económicos y culturales durante la era precolombina en esta región. Es un ejemplo representativo de la confluencia de dos culturas distintas: Inca y Española, que produjo un sincretismo cultural destacado y configuró una estructura urbana, así como formas arquitectónicas únicas (Criterio iv) (Centro del Patrimonio Mundial, 2013).

Integridad. La ciudad de Cusco mantiene la organización espacial y la mayoría de los edificios de la antigua capital del Imperio Inca y del Virreinato. A pesar del crecimiento urbano los sectores que conforman la ciudad imperial inca son reconocibles con sus antiguas estructuras de piedra y su técnica de construcción, que definen y encierran calles y canchas (unidades de vivienda), sobre las cuales se levantaron casas coloniales y republicanas, monasterios e iglesias que mantienen intactos sus elementos arquitectónicos y sus obras de arte.

Autenticidad. La autenticidad de la ciudad de Cusco está respaldada por la evidencia física de su composición urbana en calles y plazas, su distribución original con valores urbanos y arquitectónicos, el uso del espacio y la arquitectura Inca y Colonial. Características que revelan la importancia de Cusco como centro del poder político y también su simbiosis con el asentamiento colonial y los patrones del siglo $\mathrm{XV}$, lo que permite comprender mejor la ciudad y su proceso histórico. 
Requisitos de protección y gestión. La ciudad de Cusco está clasificada como Patrimonio Cultural de la Nación de acuerdo con la Resolución Suprema № 2900, de 1972. Conforme con esta regulación todas las calles en el área delimitada se clasifican como Monumental Urban Environment, y 103 edificios históricos están clasificados como Monumentos. Cusco es Patrimonio protegido por la Constitución Nacional y por la Ley $\mathrm{N}^{\circ}$ 28296, Ley General del Patrimonio Cultural Nacional, entre otros.

El Ministerio de Cultura y la Municipalidad Provincial de Cusco son los principales responsables de la conservación y gestión de la propiedad y realizan constantes evaluaciones urbanas, registro, protección, supervisión y control de obras. La Municipalidad de Cusco es responsable de autorizar obras de intervención en la ciudad y participar en la preservación y restauración de programas y proyectos de patrimonio cultural.

\section{Santuario Histórico de Machu Picchu Patrimonio Mixto Natural y Cultural}

Inscripción: $7^{\text {a }}$ Sesión del Comité del Patrimonio Mundial. Florencia, 5 de diciembre, 1983.

Está ubicado en el departamento del Cusco, provincia de Urubamba, distrito de Machu Picchu, entre los ríos Cusichaca y Aobamba, tributarios del Río Vilcanota, en el punto de encuentro entre los Andes peruanos y la cuenca del Amazonas. El Santuario Histórico de Machu Picchu es uno de los mayores logros artísticos, arquitectónicos y el legado tangible más significativo de la civilización Inca, que abarca 32592 hectáreas de laderas, picos y valles que rodean el monumento arqueológico de La Ciudadela a más de 2400 metros sobre el nivel del mar. Machu Picchu fue abandonado a comienzos del siglo XVI cuando el Imperio Inca fue conquistado por los españoles, y recién se descubrió en 1911.

La ciudad Inca del Santuario Histórico de Machu Picchu es una obra maestra de arte, urbanismo, arquitectura e ingeniería de la civilización Inca (Criterio i), con una distribución bien planificada de funciones dentro del espacio, el control del territorio y la organización social, productiva, religiosa y administrativa (Criterio iii). Los monumentos y sus características históricas están inmersos en un espectacular paisaje montañoso de excepcional belleza paisajística que muestra una relación armónica y estética entre la cultura humana y la naturaleza (Criterio vii). Cubriendo parte de la transición entre los Altos Andes y la cuenca del Amazonas, el Santuario Histórico de Machu Picchu alberga una gran variedad de microclimas, hábitats y especies de flora y fauna (Criterio ix) (Centro del Patrimonio Mundial, 2013a).

Integridad. El Santuario Histórico de Machu Picchu cumple con las condiciones de integridad, atributos y valores naturales creados por el hombre que sustentan su Valor Universal Excepcional. El conjunto visual que une el sitio arqueológico con su entorno montañoso permanece casi intacto. Y se podría extender para abarcar sitios culturales como Pisac y Ollantaytambo en el Valle Sagrado, y una parte de la cuenca del río Urubamba, lo que contribuiría a fortalecer la integridad general. En particular, la conservación de muchas especies de la flora y fauna conformada por 401 especies de aves, 19 de reptiles, 10 de anfibios, 13 de peces, 300 mariposas diurnas y 400 nocturnas; registra también 309 especies de orquídeas del total de 1625 especies existentes en el país.

Autenticidad. Después del abandono del Santuario Histórico de Machu Picchu, el crecimiento de la vegetación y el aislamiento aseguraron la conservación de sus atributos arquitectónicos. Aunque el diseño, los materiales y 
las estructuras han sufrido ligeros cambios debido a la descomposición de la tela, las condiciones de autenticidad no han cambiado. El redescubrimiento en 1911, y las posteriores excavaciones arqueológicas e intervenciones de conservación han seguido prácticas y normas internacionales que han mantenido los atributos de la propiedad.

Requisitos de protección y gestión. La Unidad de Manejo del Santuario Histórico de Machu Picchu (UGM) se estableció en 1999 para instituir las estrategias contenidas en los Planes Maestros, que son los documentos rectores actualizados regularmente para el manejo de la propiedad. La UGM fue reactivada en 2011 y está compuesta por representantes de los Ministerios de Cultura, Ministerio del Ambiente y Ministerio de Comercio Exterior y Turismo; el Gobierno Regional del Cusco, que actúa como Presidente del Comité Ejecutivo y el municipio local de Machu Picchu.

A pesar del adecuado marco legal y formal de gestión, existen desafíos para la gobernanza interinstitucional y la efectividad de la gestión y protección de la propiedad. Por ejemplo, si bien el turismo proporciona beneficios económicos también origina impactos culturales y ecológicos. El número cada vez mayor de visitantes al Santuario Histórico de Machu Picchu debe estar acompañado de una gestión adecuada que regule el acceso, diversifique la oferta y los esfuerzos para comprender y minimizar el impacto. Por ello, cobra particular importancia la evaluación y aplicación de las sugerencias contenidas en el Informe de la Misión de Monitorio Reactivo al Santuario Histórico de Machu Picchu que se realizó del 22 al 25 de febrero del 2017, efectuada por una misión presidida por César Moreno-Triana, jefe de la Unidad de América Latina y el Caribe del Centro del Patrimonio Mundial de la UNESCO.

\section{Parque Nacional Huascarán Patrimonio Natural}

Inscripción: 9a Sesión del Comité del Patrimonio Mundial. París, 2 de junio, 1985.

Situado en la Cordillera Blanca de la Región Ancash, el Parque Nacional Huascarán constituye el corazón de la cordillera tropical más alta del mundo en el centro de los Andes peruanos. La propiedad de 340000 hectáreas cubre un paisaje de montaña de alrededor de 2500 metros sobre el nivel del mar, culminando en 27 picos nevados a más de 6000 metros sobre el nivel del mar, incluyendo el Nevado Huascarán, el pico más alto del Perú con 6768 metros sobre el nivel del mar.

La amplia gama de ecosistemas y tipos de vegetación incluye bosques tropicales en algunas de las elevaciones y valles más bajos. Diversos tipos de pastizales y matorrales de páramo y puna son los tipos de vegetación dominantes en las zonas más altas que hacen la transición hacia la tundra tropical. El Parque Nacional Huascarán es el hogar de la emblemática Vicuña, significando uno de los éxitos de conservación más importantes de América del Sur. Entre los mamíferos figuran el ciervo del norte de los Andes, el puma o el león de montaña, el oso de anteojos vulnerable y el gato de montaña andino en peligro de extinción. La avifauna cuenta con más de 100 especies registradas, entre ellas, el cóndor andino y el colibrí gigante. Se han documentado alrededor de 800 especies de plantas, siendo la más famosa la Reina de los Andes, en peligro de extinción. Además, hay pinturas rupestres notables, tumbas de piedra e innumerables artefactos (Criterio vii y Criterio viii) (Centro del Patrimonio Mundial, 2015). 
Integridad. El Parque Nacional Huascarán cubre una extensa área de terreno montañoso accidentado con una amplia gama de valores naturales. La reserva de la biosfera cubre la Cordillera Blanca casi en su totalidad, ofreciendo la posibilidad de administrar la propiedad a nivel del paisaje. Los factores naturales que contribuyen a la integridad del Parque Nacional Huascarán incluyen la gran altitud, las condiciones climáticas severas y la topografía accidentada. Aunque Huascarán está inscrito en la Lista del Patrimonio Mundial por sus valores de conservación de la naturaleza, también es famoso por sus valores arqueológicos. Existen restos de antiguas culturas gracias a la apartada ubicación y a las duras condiciones ambientales en vastas áreas de la propiedad.

Requisitos de gestión y protección. En la década de 1960, la extinción inminente de la Vicuña, y la preocupación por la Reina de los Andes, originaron la creación de una zona de vigilancia que actualmente es parte de la propiedad. Posteriormente, el Parque Nacional Huascarán se estableció en 1975 por Decreto Supremo en el marco general de la legislación nacional sobre bosques y vida silvestre. El parque nacional también constituye la zona núcleo de la Reserva de la Biosfera Huascarán a partir del reconocimiento de la UNESCO en 1977.

Desde su establecimiento la falta de un adecuado presupuesto y de personal idóneo, ha originado dificultades para responder a los desafíos que enfrenta. Las comunidades cercanas a la propiedad están creciendo, sobre todo en el Callejón de Huaylas, un valle al oeste del Parque Nacional Huascarán. A pesar de que la legislación prohíbe la extracción de recursos minerales en parques nacionales, hay concesiones dentro de la propiedad y planes para la construcción de presas. También existe riesgos de impactos ambientales y culturales que podría originar el turismo.

\section{Sitio Arqueológico de Chavín de Huántar Patrimonio Cultural}

Inscripción: 9a Sesión del Comité del Patrimonio Mundial. París, 2 de junio, 1985.

El sitio arqueológico de Chavín de Huántar debe su nombre a la cultura que se desarrolló entre los siglos XIII y V a. C., ubicado en la provincia de Huari, departamento de Ancash, en la unión de los ríos Huachecsa y Mosna, tributarios del Río Marañón; sobre el flanco oriental de la Cordillera Blanca y el Callejón de Conchucos, a 3180 m s. n. m. Chavín fue un centro ceremonial y de peregrinación que acogió a personas de diferentes latitudes, distancias e idiomas, convirtiéndose en un importante lugar de convergencia cultural y religiosa. El área declarada Patrimonio Mundial tiene una extensión de 14.79 ha y un perímetro de 1911.014 m. Está conformado por un conjunto de estructuras monumentales distribuidas dentro de un patrón arquitectónico que caracterizó al periodo Horizonte Temprano debidamente cercado y bajo protección legal mediante RDN $\mathrm{N}^{\circ}$ 1056/INC del 21 de agosto de 2007, que aprobó el expediente técnico de la Zona Arqueológica Monumental Chavín de Huántar y la declaró Patrimonio Cultural de la Nación.

El 18 de julio del 2008 se inauguró el Museo Nacional Chavín con el objeto de difundir y promocionar los valores universales del monumento y la sociedad Chavín. Es uno de los sitios precolombinos más antiguos y conocidos, expresión de las artes y las técnicas decorativas y de construcción de su tiempo. Su creación arquitectónica, tecnológica y simbólica, que se caracteriza por edificios revestidos de piedra de cantera y terrazas artificiales alrededor de plazas, que contiene un sistema interno de galería con una intrincada red de respiraderos y desagües sin precedentes en América del Sur. Es un ejemplo excepcional de las creaciones arquitectónicas, tecnológicas y simbólicas de las 
primeras sociedades precolombinas en los Andes peruanos. Su aspecto es sorprendente, con una serie de terrazas y plazas, con un complejo sistema de galerías internas, y decorado con elementos iconográficos antropomórficos y zoomorfos de gran belleza (Criterio iii)(Centro del Patrimonio Mundial, 2013b)

Integridad. Los límites de la propiedad contienen todos los elementos, características y valores estructurales y simbólicos del complejo arquitectónico y de su evolución histórica que transmiten su Valor Universal Excepcional. Aunque el sitio ha sido históricamente afectado por fenómenos naturales y antropogénicos, conserva la integridad del complejo formado por los edificios, plataformas y plazas, su diseño arquitectónico, las formas y materiales originales de sus diferentes etapas de construcción; las estructuras, galerías, plazas y espacios arquitectónicos conservan elementos y características originales, incluida la iconografía, revelando su uso y función originales.

Autenticidad. Se han mantenido las condiciones de autenticidad del sitio arqueológico de Chavín, incluida la planificación del territorio y su concepción arquitectónica, formas, materiales y diseño iconográfico. Los elementos existentes en el sitio son testigos del diseño, desarrollo y síntesis del arte lítico estético de las lápidas, vigas, columnas, esculturas y otros que permanecen in situ, y muestran sus connotaciones ideológicas religiosas, el simbolismo y el significado ritual del compuesto, y el uso ceremonial y la función de espacios y áreas arquitectónicas en particular. También representan la sociedad de Chavín y el proceso de evolución histórica que revela diferentes etapas de construcción y contextos culturales.

Requisitos de protección y gestión. El sitio arqueológico de Chavín está debidamente protegido por la Constitución Nacional (Art. 36), la Ley Nº634 del 13 de junio de 1929 que estipula expresamente el derecho inalienable e irrevocable de la nación sobre todos los monumentos existentes antes del Virreinato en el país y declara el sitio arqueológico de Chavín como monumento nacional. Otras normas legales para la protección incluyen la Ley General del Patrimonio Cultural Nacional ( $\left.\mathrm{N}^{\circ} 28296\right)$ que establece que el patrimonio cultural de la nación es inalienable e imprescriptible, y la Ley $\mathrm{N}^{\circ} 13442$ que determina la creación del Parque Nacional Chavín y el Centro del Turismo Arqueológico en la provincia de Huari, departamento de Ancash.

\section{Zona Arqueológica Chan Chan Patrimonio Cultural. Lista en peligro}

Inscripción: 10ª Sesión del Comité del Patrimonio Mundial. París, 24 de noviembre, 1986.

Chan Chan fue la capital política, administrativa y religiosa de la Cultura Chimú que alcanzó su apogeo en el siglo XV, poco antes de caer en dominio de los Incas. Está ubicada en el valle fluvial de Moche o Santa Catalina, y es la ciudad de arquitectura de tierra más grande en la América precolombina. Su trazado refleja una precisa estrategia política y social, enfatizada por su división en nueve 'ciudadelas' o 'palacios' que forman unidades independientes. El Valor Universal Excepcional de Chan Chan reside en los extensos y planeados restos jerárquicos de esta ciudad, incluidos los restos de los sistemas industriales, agrícolas y de gestión del agua que la sustentaron.

La zona monumental de alrededor de seis kilómetros cuadrados en el centro de la ciudad que alguna vez fue de veinte kilómetros cuadrados, comprende nueve grandes complejos rectangulares ('ciudadelas’ o 'palacios') delineados por altas y gruesas paredes de tierra, que incluyen templos, viviendas y almacenes dispuestos alrededor de espacios abiertos. Las paredes de tierra están decoradas con frisos que representan motivos abstractos, 
antropomorfos y zoomorfos. La planificación de la ciudad de tierra más grande de la América precolombina es una obra maestra de organización urbana. La zonificación rigurosa, el uso diferenciado del espacio habitado y la construcción jerárquica ilustran un ideal político (Criterio i). Chan Chan significa un testimonio único y es la ciudad más representativa del dominio Chimú donde se sintetizan y expresan once mil años de evolución cultural en el norte del Perú (Criterio iii) (Centro del Patrimonio Mundial, 2011).

Integridad. Chan Chan conserva todos los elementos que llevan su Valor Universal Excepcional en un área de catorce kilómetros cuadrados, que aunque es menor que el área original de la ciudad, contiene características representativas de las unidades arquitectónicas, caminos ceremoniales, templos y unidades agrícolas. La construcción de tierra de la ciudad, así como las condiciones ambientales, incluidas las condiciones climáticas hacen que el sitio arqueológico sea susceptible de descomposición y deterioro.

Autenticidad. El sitio arqueológico todavía expresa la esencia del paisaje urbano monumental de la antigua capital Chimú. También los arreglos jerárquicos que reflejan la complejidad política, social, tecnológica, ideológica y económica alcanzada por la sociedad Chimú entre los siglos IX y XV. La arquitectura de tierra original con su característica religiosa y decoraciones, aunque sujeta a deterioro, está siendo sometida a intervenciones de conservación de materiales de barro y aún representa fielmente los métodos de construcción y el espíritu de la gente.

Protección y requisitos de gestión. El Ministerio de Cultura del Perú, a través de su oficina descentralizada en La Libertad, tiene a su cargo la conservación y defensa de Chan Chan, que está protegida por leyes y decretos nacionales. Sin embargo, su ubicación frente al mar acarrea sales y humedad que afectan los muros de barro, y las intensas lluvias cíclicas del fenómeno El Niño debilitan sus estructuras. Además de problemas como la tenencia de la tierra y las prácticas agrícolas ilegales. Frente a lo cual, el cumplimiento de las medidas reglamentarias aún no se han resuelto eficazmente para garantizar la conservación y la protección de la propiedad

que fue incluida en la Lista del Patrimonio Mundial en Peligro en 1986 debido al precario estado de conservación de la arquitectura de tierra y su vulnerabilidad. Igualmente, las ruinas están amenazadas por el constante saqueo de restos arqueológicos y por la propuesta de construir una carretera que cruza el sitio.

Desde su inscripción se han tomado varias medidas para eliminar la propiedad de la Lista del Patrimonio Mundial en Peligro, incluida la ejecución de medidas correctivas y el desarrollo de un plan de gestión, cuya implementación ha involucrado principalmente el mantenimiento de drenajes que controlan el nivel freático, estabilización de muros perimetrales de palacios y plataformas funerarias, control de vegetación, mantenimiento de áreas de uso público, documentación arquitectónica para conservación y gestión, desarrollo de capacidades para artesanos locales y medidas para crear conciencia en los estudiantes y la comunidad local.

\section{Parque Nacional del Manu Patrimonio Natural}

Inscripción: 11ª Sesión del Comité del Patrimonio Mundial. París, 7 de diciembre, 1987.

El Parque Nacional del Manu está ubicado entre las Regiones Madre de Dios y el Cusco, punto de encuentro de los Andes Tropicales y la cuenca del Amazonas en el suroeste del Perú. Es una de las reservas naturales más importantes de la región amazónica que cuenta con más de 1000000 ha de extensión y una diversidad biológica 
relevante que se desarrolla entre los 150 a 4100 m s. n. m. ${ }^{5}$ Aquí coexisten miles de variedades de plantas, especies de aves, mamíferos, anfibios, insectos y especies raras; por esta razón el Manú se ha convertido en un lugar de investigación y estudio para científicos de todo el mundo.

Se trata de una cuenca hidrográfica extensa, geográfica y económicamente aislada, a la que es difícil de acceder por lo que no ha sufrido mayores impactos humanos. Alimentado por numerosos arroyos de aguas de las montañas, el río Manu avanza a través de los bosques de las tierras bajas, antes de unirse al río Madre de Dios en el extremo sur. Como lo demuestran las ruinas y los petroglifos incaicos y preincaicos, existe una larga historia de presencia humana. La leyenda de Paititi, que según las crónicas de la época y las leyendas habría sido una ciudad Inca escondida en alguna parte de la selva amazónica peruana, ha atraído a investigadores y aventureros.

El Parque Nacional del Manu posee una amplia gama de condiciones ecológicas y de evolución de numerosas especies y comunidades (Criterio ix). Diversidad de plantas que oscilan entre 2000 y 5000, y se distribuyen a través de los diversos ecosistemas, hábitats y nichos. Más de 200 especies de mamíferos, 800 especies de aves, 68 especies de reptiles, especies raras como el armadillo gigante, 77 especies de anfibios y una impresionante cantidad de peces de agua dulce, Más de 1300 especies registradas de mariposas, insectos, y cientos de especies arbóreas ya identificadas (Criterio x) (Centro del Patrimonio Mundial, 2015a).

Integridad. La propiedad se beneficia de una protección natural debido a su ubicación y se considera una de las áreas primigenias de la Amazonía peruana. Está integrada en un complejo de conservación compuesto por diferentes categorías de áreas protegidas y áreas comunales indígenas, incluyendo el Parque Nacional Alto Purus y el Santuario Nacional Megantoni. Hay corredores funcionales que se extienden hasta la Amazonía brasileña y boliviana. El uso humano directo y la interferencia son mínimos y se limitan a un pequeño número de residentes indígenas.

Requisitos de protección y gestión. El aislamiento geográfico y la protección han favorecido al Parque Nacional Manu, en comparación con los cambios que se han producido en otras regiones de la Amazonía peruana. La historia formal de conservación empezó en 1968, cuando se declaró la Reserva Natural Manu. En 1977, el Parque Nacional Manu fue reconocido por la UNESCO como la zona núcleo de una reserva de biosfera aún mayor. Tanto el parque nacional como la reserva de la biosfera están bajo la autoridad del Servicio Nacional de Áreas Naturales Protegidas por el Estado, SERNANP, que depende del Ministerio del Ambiente (MINAM). El parque posee varias zonas, la más grande es la Zona restringida, principalmente de bosques no intervenidos y dedicada a la conservación con acceso restringido para los investigadores, y las más pequeñas son la Zona de Uso Especial y la Zona de Servicio alrededor de la Estación Biológica Cocha Cashu. También dos Zonas Recreativas, una Zona Cultural y una Zona de Recuperación que cubre áreas andinas afectadas por el ganado y el uso relacionado con el fuego. Tanto las comunidades agrícolas como los residentes indígenas tienen un impacto localizado pero manejable. Pero existe preocupación ante la construcción de nuevos caminos a través de los Andes, y por el impacto de la explotación del yacimiento de gas de Camisea.

5 http://www.perubicentenario.pe:80/turismo/patrimonio_ciudad_cusco.html 


\section{Centro Histórico de Lima Patrimonio Cultural}

Inscripción: 12ª Sesión del Comité del Patrimonio Mundial. Brasilia, 5 de setiembre, 1988.

Ampliación del Área Inscrita: 15ª Sesión del Comité del Patrimonio Mundial. Cartago, 9 de diciembre, 1991.

El Centro Histórico de Lima se encuentra en el valle del Rímac. Lima, fundada por el conquistador español Francisco Pizarro en enero de 1535, fue la capital política, administrativa, religiosa y económica del Virreinato del Perú, y la ciudad más importante de los dominios españoles en América del Sur. El proceso de evangelización a fines del siglo XVI permitió la llegada de varias órdenes religiosas y la construcción de iglesias y conventos. La Universidad de San Marcos, Decana de América, se fundó el 12 de mayo de 1551, e inició sus funciones el 2 de enero de 1553 en el Convento de Santo Domingo.

Se puede apreciar en el Centro Histórico de Lima: la Plaza de Armas con la Catedral, la capilla del Sagrario, el Palacio del Arzobispado, la Iglesia de Santo Domingo y el convento de San Francisco. También varias obras públicas construidas durante el período virreinal como el puente de piedra sobre el río Rímac, el Paseo de Aguas, la Alameda de los Descalzos, la Plaza de Toros de Acho y el cementerio general llamado Presbítero Maestro. La arquitectura se caracterizó por fachadas, pasillos, patios y balcones con ligeras variaciones en el estilo durante el período republicano hasta finales del siglo XIX, cuando comenzó la «modernización» urbana y la nueva arquitectura europea (Centro del Patrimonio Mundial, 2013c).

Integridad. Aunque fue seriamente dañada por los terremotos de 1940, 1966, 1970 y 1974, el área del centro histórico de Lima conserva todos los elementos y características físicas que transmiten su Valor Universal Excepcional, en una extensión que incluye además del trazado urbano, testimonios de arquitectura civil doméstica, pública, religiosa, militar e industrial de los siglos XVII al XX.

Autenticidad. La legitimidad del centro histórico de Lima está intacta porque conserva en gran medida las características originales de su diseño de cimentación urbana, y el área de expansión del siglo XVI al XIX, incluidos antiguos caminos prehispánicos que se dirigen al Norte (Chinchaysuyo) y Este (Antisuyo). Los edificios públicos, privados y religiosos conservan sus valores arquitectónicos, tecnológicos, tipológicos, estéticos, históricos y urbanos, resultado de la implantación de estilos europeos de diferentes etapas del proceso de evolución histórica de la ciudad desde el siglo XVI hasta el siglo XX.

Requisitos de protección y gestión. Al margen del deterioro natural que afecta la integridad material de los edificios, el centro histórico de Lima enfrenta factores adicionales que lo degradan en términos ambientales y urbanos como la explotación comercial en zonas de estructuras antiguas para construir 'centros comerciales', así como la fuerte presencia de transporte público y privado que genera contaminación. Otro factor, es el aumento de población como resultado de la inmigración proveniente de las otras regiones del país hacia Lima, 1940: 400,000. 1990: 7’000,000. 2017: 9’000,000.

El Centro Histórico de Lima está protegido por la Constitución Política del Estado; Ley N$^{\circ}$ 28296, Ley General de Patrimonio Cultural de la Nación Resolución N²900 de 1972 que lo declara Zona Monumental con edificios con valor patrimonial como Monumentos Nacionales, la Resolución Ministerial №505-74-ED de 
1974, Resolución Ministerial № 0928- 80-ED de 1980, y Resolución Ministerial № 1251-1985-ED de 1985. El Municipio Metropolitano de Lima comparte la responsabilidad de la gestión del Centro Histórico de Lima con el Municipio del Distrito del Rímac. El Ministerio de Cultura está a cargo de la preservación del patrimonio cultural de la Nación y cuenta con una Oficina de Control Urbano y la Empresa Municipal de Bienes Raíces de Lima (EMILIMA) a cargo de la planificación y preparación de proyectos de gestión como: el Plan de Desarrollo Metropolitano y el Plan del Centro Histórico de Lima (1987), que establecen pautas básicas, intervenciones y proyectos relacionados con la situación y estructura urbana, medio ambiente, uso del suelo, sistema de transporte, habitabilidad y dinámica.

\section{Parque Nacional del Río Abiseo Patrimonio Mixto}

Inscripción: 1990 - 1992

El Parque Nacional Río Abiseo se creó en 1983, en territorio de la provincia Mariscal Cáceres, parte Nororiental del la Región San Martín. Es uno de los pocos bienes Patrimonio de la Humanidad inscritos en valores culturales y naturales. Como Unidad de Conservación su territorio comprende dos zonas diferenciadas: la Zona Restringida y la Zona de Amortiguamiento. La Zona Restringida consiste en el Parque y tiene una superficie de 274520 hectáreas. La Zona de Amortiguamiento se ubica alrededor de la anterior, con una superficie de 672713 hectáreas. Aquí la propiedad alberga varios tipos de bosques y pastizales altoandinos.

La cantidad y variedad de sitios arqueológicos encontrados indican que existió ocupación humana desde la época precerámica alrededor de 6000 años a. C. y que continuó hasta antes de la colonización española. Desde 1985, se han registrado 36 sitios arqueológicos, 29 en los pastizales de alta elevación y siete en los bosques del parque. La propiedad protege las cabeceras de tres ríos del sistema Huallaga, un importante afluente del Amazonas. Las praderas andinas como los bosques de tierras bajas, montañosas y nubosas, poseen un importante número de especies, entre las que destaca el mono lanudo de cola amarilla, una de las especies de monos más grandes de América del Sur.

Los monumentos prehispánicos en el valle de Montecristo dentro del Parque Nacional del Río Abiseo constituyen ejemplos destacados de adaptación, evolución y asentamiento humano en los bosques de altura de la cuenca amazónica de los Andes peruanos (Criterio iii). El Parque Nacional Río Abiseo alberga una cuenca hidrográfica cubierta de densos bosques. La gran belleza del variado paisaje montañoso se complementa con numerosos pequeños lagos de montaña, piscinas, ríos, arroyos y cañones escarpados (Criterio vii). A lo largo del enorme gradiente altitudinal de alrededor de 350 a 4349 metros sobre el nivel del mar, influenciado por suelos altamente variables, exposiciones, patrones de lluvia y microclimas, la propiedad posee ecosistemas y hábitats muy variados (Criterio ix) (Centro del Patrimonio Mundial, 2015b).

Así mismo, se han registrado más de 5000 especies de plantas, y casi 1000 en las praderas. Los estudios taxonómicos indican especies desconocidas para la ciencia, incluidos los vertebrados, como reptiles, anfibios e incluso pequeños mamíferos. La fauna de mamíferos incluye el oso de anteojos, el armadillo gigante, el ciervo del norte de los Andes, el jaguar y varias otras especies de gatos. Cientos de especies de aves e innumerables artrópodos se distribuyen a través de los hábitats y nichos ecológicos (Criterio x). 
Integridad. El Parque Nacional del Río Abiseo contiene desde refugios rocosos hasta estructuras de viviendas, ceremonias, producción (plataformas y almacenes), cementerios y caminos que permanecen intactos a pesar del tiempo, con características naturales y culturales de importancia para la conservación y la investigación. Desde la perspectiva del patrimonio natural, es notable que el gradiente altitudinal total de las tierras bajas a los pastizales altoandinos goza de plena protección.

Autenticidad. La configuración geográfica, el aislamiento y la inaccesibilidad del área, han contribuido a mantener intacto el Parque Nacional del Río Abiseo, así como también la autenticidad de sus restos arqueológicos. No se han producido intervenciones humanas significativas desde su abandono en el siglo XVI hasta su redescubrimiento en el siglo XIX. Estas condiciones muestran que la diversidad de sitios arqueológicos dentro de las diversas altitudes y áreas del Parque Nacional del Río Abiseo atestiguan el proceso y la continuidad histórica de adaptación, evolución y desarrollo humano.

Requisitos de protección y gestión. La falta de infraestructura y el difícil acceso a la mayor parte de la propiedad han asegurado un grado importante de protección contra las perturbaciones y actividades ilegales. En 1983, veinte años después de su descubrimiento científico, el sitio arqueológico de la Ciudadela del Gran Pajatén se consignó como Patrimonio Cultural Nacional. El mismo año, el Parque Nacional del Río Abiseo se estableció con el objetivo de proteger el bosque nuboso excepcional, la cuenca hidrográfica de Abiseo y los valores culturales de la zona. Desde el principio, el Ministerio de Agricultura (y posteriormente el Ministerio del Ambiente) y el Instituto Nacional de Cultura, actualmente Ministerio de Cultura, han compartido la responsabilidad formal de la gestión. A pesar del evidente potencial turístico del paisaje y de los sitios arqueológicos, las visitas públicas están restringidas debido a la fragilidad de la propiedad.

\section{Líneas y geoglifos de Nazca y Pampas de Jumana Patrimonio Cultural}

Inscripción: 18ª Sesión del Comité del Patrimonio Mundial. Phuket, 12 de diciembre, 1994.

Ubicadas en la costa desértica peruana a unos $400 \mathrm{~km}$ al sur de Lima, en el departamento de Ica, las Líneas y Geoglifos de Nazca y Pampas de Jumana se descubrieron en 1927, y constituyen el legado más importante de la sociedad Nazca, que se desarrolló hace 2300 años, entre los 100 a. C. y 600 d. C. correspondiente al período Intermedio Temprano de la secuencia cultural andina. ${ }^{6}$

El sitio arqueológico cubre un área de aproximadamente 75358 ha, y fue asiento de los antiguos habitantes de la región que dibujaron en el suelo árido una extraordinaria variedad de figuras geométricas, de animales y divinidades, que solo pueden ser apreciadas desde lo alto, transformando la extensa costa en un paisaje cultural simbólico, ritual y social que permanece hasta nuestros días. Las Líneas y Geoglifos de Nazca constituyen un producto artístico único de la cultura andina por su extensión, dimensión y diversidad, que no tiene parangón en el mundo prehistórico (Criterio i). A través de su uso de la tierra, es un testimonio excepcional de la cultura, la tradición y las creencias de las sociedades que se desarrollaron en el período precolombino en América del Sur,

$6 \quad$ http://www.perubicentenario.pe:80/turismo/patrimonio_ciudad_cusco.html 
entre lo mágico-religioso de los siglos VIII a. C. y VIII d. C. (Criterio iii). El sistema de líneas y geoglifos, que ha perdurado intacto durante más de dos milenios, evidencia una forma inusual de utilizar la tierra y el entorno natural que representan un paisaje cultural altamente simbólico, aplicando una tecnología de construcción que les permitió diseñar figuras a gran escala con una precisión geométrica prominente (Criterio iv) (Centro del Patrimonio Mundial, 2015c).

Hay dos categorías de glifos: el primer grupo representa en forma esquemática una variedad de formas naturales que incluyen animales, pájaros, insectos, flores, plantas y árboles, y objetos de la vida cotidiana. El segundo grupo comprende líneas generalmente rectas que cruzan la pampa en todas las direcciones. Algunas tienen varios kilómetros de longitud y forman diseños de figuras geométricas: triángulos, espirales, líneas onduladas. Otro grupo son las llamadas ‘pistas', al parecer diseñadas para acomodar a un gran número de personas.

Integridad. Las líneas y geoglifos de Nazca y Pampas de Jumana en un área de protección que se extiende sobre 75358 ha, transmiten el Valor Universal Excepcional de la propiedad, incluyendo su paisaje circundante conformando una unidad armoniosa que ha sobrevivido prácticamente inalterada a lo largo de los siglos. Las tasas de precipitación bajas (las más bajas del mundo), determinan las características del clima del desierto y la extrema aridez que han favorecido la conservación de las líneas y Geoglifos de Nazca. Así mismo, la actividad humana no ha causado un impacto severo en la propiedad, por lo que los geoglifos y el paisaje cultural se han mantenido intactos durante casi dos milenios. Sin embargo, la construcción de la Carretera Panamericana Sur, que cruza directamente la propiedad, ha causado daños en algunos sectores de las líneas y figuras.

Autenticidad. La creación, diseño, morfología, tamaño y variedad de los geoglifos y líneas corresponden a los diseños originales producidos durante la evolución histórica de la región y se han mantenido sin cambios. La ideología, el simbolismo y el carácter sagrado y ritual de los geoglifos y el paisaje están claramente representados, y su significado permanece intacto hasta la actualidad.

Requisitos de protección y gestión. La Constitución Nacional (Art. 36) y la Ley N²28296, Ley General del Patrimonio Cultural Nacional, son las principales normas de protección legal para las Líneas y Geoglifos de Nazca y Pampas de Jumana. Los límites del área de protección se establecieron mediante la Resolución № 421 / INC como Reserva Arqueológica. Desde 1941 científicos extranjeros, especialmente la Dra. María Reiche, han realizado investigaciones arqueológicas, de conservación, protección y medidas de mantenimiento de las Líneas y Geoglifos de Nazca. La gestión y protección es responsabilidad del Gobierno peruano representado por el Ministerio de Cultura. Se ha formulado y se está implementando un plan de gestión para toda el área, que es fundamental para la protección de las líneas y geoglifos de Nazca y Palpa.

\section{Centro Histórico de la Ciudad de Arequipa Patrimonio Cultural}

Inscripción: 24 Sesión del Comité del Patrimonio Mundial. El Cairo, 27 de noviembre, 2000.

El Centro Histórico de Arequipa representa la combinación de influencias nativas y características de construcción española en un terreno inestable debido a terremotos, formado por gruesas paredes, arcos, pórticos, bóvedas, patios y espacios abiertos construidos principalmente con sillar, la piedra volcánica que proviene del 
volcán el Misti. Las poblaciones indígenas preexistentes, la conquista y la evangelización española, el entorno natural y los frecuentes terremotos, son factores principales en la definición de la identidad de Arequipa. La ciudad fue fundada en 1540 en un valle que había sido intensamente cultivado por comunidades prehispánicas. El diseño de una aldea indígena ha sobrevivido cerca del Centro Histórico en el distrito de San Lázaro. El sitio del Patrimonio Mundial consta de 49 bloques originales del diseño español.

La arquitectura ornamentada en el Centro Histórico de Arequipa representa una obra maestra de la integración creativa de características europeas y nativas, cruciales para la expresión cultural de toda la región (Criterio i). El Centro Histórico de Arequipa es un ejemplo de asentamiento colonial, con influencias indígenas, el proceso de conquista y evangelización (Criterio iv)(Centro del Patrimonio Mundial, 2015d). Aquí es posible identificar cinco períodos: la fundación (1540-1582), el esplendor barroco (1582-1784), la introducción del rococó y el neoclasicismo (1784-1868), el empirismo moderno y la moda neoclásica (1868-1960). El núcleo de la ciudad histórica es la Plaza de Armas (Plaza Mayor) con sus arcos, el municipio y la catedral. En una esquina de la plaza se encuentran la iglesia y los claustros de La Compañía, el conjunto más representativo del período barroco mestizo de finales del siglo XVIII. El Monasterio de Santa Catalina es una impresionante ciudadela religiosa que integra estilos arquitectónicos de los siglos XVI al XIX. El complejo de San Francisco incluye una pequeña plaza, la iglesia principal, el convento y los claustros de la tercera orden. Las capillas y conventos de Santo Domingo datan de los siglos XVI al XVIII: San Agustín, La Merced y la iglesia de Santa María; Santa Teresa y Santa Rosa. El Puente Real (ahora Puente Bolognesi) y el Puente Grau también están construidos de sillar.

Integridad. El área de protección del Centro Histórico de Arequipa comprende 166.52 ha, abarca todos los elementos representativos y las características físicas del complejo urbano y arquitectónico y su evolución histórica, que expresa el Valor Universal Excepcional del sitio. El diseño urbano fundacional de la ciudad, sus entornos urbanos monumentales y edificios religiosos y civiles construidos entre los siglos XVII y XX, conforman su carácter urbano histórico. El Centro Histórico de Arequipa se integra al entorno natural y cultural del valle del río Chili, coronado por tres volcanes nevados. Estos atributos conservan y mantienen una relación armoniosa sin alteraciones significativas.

Autenticidad. La planificación del trazado urbano del Centro Histórico de Arequipa mantiene su originalidad y gran parte del tejido urbano que expresa el carácter mixto de la ciudad y su identidad histórica. Las técnicas de construcción con piedra volcánica y el fino trabajo escultórico de pórticos y otras estructuras en sillar también atestiguan el desarrollo tecnológico y el arte barroco que ha sobrevivido desde el siglo XVII. Las iglesias mantienen su uso religioso; sin embargo, muchas casas solariegas han perdido su uso original como residencias.

Requisitos de protección y gestión. El Centro Histórico de Arequipa está protegido por la Constitución Nacional y por la Ley N²8296, Ley General del Patrimonio Cultural Nacional de 2004. La Resolución Suprema N 2900, de 1972, declara el Centro Histórico de Arequipa como Área Monumental con un valor patrimonial. El Decreto Supremo N 012-77-IT / DS de 1977 define los límites del área monumental, y la Ordenanza municipal № 13-99 determina la protección y crea la Superintendencia Municipal de Gestión y Control del Centro Histórico de Arequipa. La tarea fundamental es proteger la ciudad de fenómenos naturales: actividad sísmica, volcánica de baja intensidad y El Niño-Oscilación del Sur (ENSO). Así mismo, el centro de la ciudad soporta una 
sobrepoblación, intenso tráfico vehicular y contaminación, comercio formal e informal, y la demolición de propiedades inmobiliarias para ser utilizadas como estacionamientos o tiendas comerciales.

\section{Ciudad Sagrada de Caral - Supe, Patrimonio Cultural}

Inscripción: 33ª Sesión del Comité del Patrimonio Mundial. Sevilla, 28 de junio, 2009.

La Ciudad Sagrada de Caral - Supe representa a la civilización más antigua de América, y expresa el surgimiento de un estado sociopolítico, notable por su complejidad y su impacto en el desarrollo de asentamientos en todo el valle de Supe. Su uso temprano del quipu como dispositivo de grabación se considera de gran importancia. El diseño de los componentes arquitectónicos y espaciales de la ciudad es magistral, y los montículos de plataformas monumentales y los patios circulares empotrados son expresiones de un estado consolidado.

Caral es la mejor representación de la arquitectura arcaica tardía y del urbanismo en la antigua civilización peruana. Los montículos plataforma, las canchas circulares hundidas y el plan urbano, que se desarrolló durante siglos, influyeron en los asentamientos cercanos y, posteriormente, en gran parte de la costa peruana (Criterio ii). En el valle de Supe está la primera manifestación de civilización conocida en las Américas, Caral es el ejemplo de asentamiento más desarrollado y complejo del período formativo de la civilización (el período arcaico tardío) (Criterio iii). Caral es impresionante en términos del diseño y la complejidad de sus elementos arquitectónicos y espaciales, especialmente sus montículos monumentales de plataforma de tierra y las canchas circulares hundidas, características que dominarían gran parte de la costa peruana durante muchos siglos (Criterio iv) (Centro del Patrimonio Mundial, 2009).

Integridad y autenticidad. Caral está notablemente intacta debido en gran parte a su abandono temprano y descubrimiento tardío. Una vez abandonada, parece haber sido ocupada solo dos veces, y luego una en el llamado Formativo Medio u Horizonte Temprano, alrededor de 1000 a. C.; y en el período de los Estados y señoríos, entre 900 y 1440 d. C. Como ambos asentamientos estaban en las afueras de la ciudad, no perturbaron las estructuras arquitectónicas antiguas. Además, como el sitio carecía de descubrimientos de oro y plata, hubo pocos saqueos. El sitio es parte de un paisaje cultural y natural de gran belleza, relativamente intacto. La mayor parte del desarrollo se ha producido en las áreas bajas del valle cerca de Lima (al sur del sitio). El valle medio de Supe, donde se encuentra el sitio, es un área dedicada a la agricultura. El análisis de radiocarbono realizado por el Proyecto Arqueológico Especial Caral - Supe (PEACS) en el sitio de Caral confirma que su desarrollo se puede ubicar entre los años 3000 a 1800 a. C. y, específicamente, al período Arcaico Tardío.

Requisitos de gestión y protección. El sistema de gestión en funcionamiento es adecuado y se ha implementado un plan de gestión modificado a fines del 2008, que incluye regulaciones para garantizar la preservación y conservación de la propiedad.

\section{Qhapaq Ñan, Sistema Vial Andino, Patrimonio Cultural}

Inscripción: 38 Sesión del Comité del Patrimonio Mundial. Doha, Qatar, 21 de junio, 2014.

Qhapaq Ñan, es un extenso camino inca con más de 30000 km construido por las culturas prehispánicas andinas durante varios siglos. Alcanzó su máxima expansión en el siglo XV, durante la consolidación del Tahuantinsuyo. 
Atraviesa seis países: Argentina, Bolivia, Chile, Colombia, Ecuador, Perú, y tiene cuatro rutas principales que parten de la plaza central de Cusco, capital del Imperio de los Incas. Estas rutas están conectadas con otros caminos creando vínculos y conexiones con una infraestructura asociada para el comercio, almacenamiento y alojamiento.

El Qhapaq Ñan fue el camino que unía ciudades, cultos y centros de producción durante varios siglos. Significa un logro único de ingeniería en un terreno geográfico que une las montañas nevadas de los Andes con una altitud de más de 6600 m s. n. m. con los valles fértiles de la Amazonía. La integración del conocimiento ancestral de las comunidades y culturas andinas permitió el intercambio de valores sociales, políticos y económicos. Varias estructuras en el camino proporcionan evidencia de recursos valiosos y bienes comercializados como metales preciosos, muyu (concha de Spondylus), alimentos, suministros militares, plumas, madera, coca y textiles transportados desde las áreas donde fueron recolectados, producidos o fabricado, a centros incas y a la capital (Criterio ii) (Centro del Patrimonio Mundial, 2014).

El Qhapaq Ñan fue el soporte vital del Imperio Inca y símbolo de su fuerza y extensión (Criterio iii). Varios elementos ilustran las tipologías características en términos de muros, caminos, escalones, zanjas de caminos, tuberías de aguas residuales, desagües, etc., con métodos de construcción exclusivos variando según su ubicación y el contexto regional (Criterio iv). El sistema vial andino, jugó un papel esencial en la organización del espacio y la sociedad en una amplia área geográfica a lo largo de los Andes, donde los caminos fueron utilizados como un medio para compartir valores culturales, proporcionar a las comunidades un sentido de identidad y permitir que sus prácticas y expresiones culturales continúen transmitiéndose de generación en generación (Criterio vi).

Integridad. La serie de sitios inscritos del Qhapaq Ñan ilustra la variedad de elementos tipológicos, funcionales y comunicativos, que permiten una comprensión completa de su rol histórico y contemporáneo. El número de segmentos es adecuado para comunicar las características principales de la ruta del patrimonio, a pesar de que están fragmentados en componentes individuales.

Autenticidad. Los sitios del Qhapaq Ñan conservan las características, su forma, diseño, y la variedad de tipos arquitectónicos y de ingeniería específicos. Los materiales utilizados son principalmente de piedra y tierra, con tipos que varían de región a región, y las medidas de reparación y mantenimiento se llevan a cabo con técnicas y materiales tradicionales. El Qhapaq Ñan atraviesa paisajes que necesitan ser monitoreados para asegurar que el desarrollo moderno no tenga un impacto visual. Varios sitios son de difícil acceso y su lejanía los ha mantenido en buenas condiciones durante siglos.

Requisitos de protección y gestión. Qhapaq Ñan atraviesa seis países que han firmado declaraciones conjuntas, entre los años 2010 y 2012, de protección siguiendo sus respectivas legislaciones. En los contextos nacionales, los sistemas de gestión se han desarrollado en cooperación con las comunidades locales, pues la mayoría expresó su interés en actividades turísticas que pretenden ser administradas y conducidas a nivel comunitario. Algunos territorios del Qhapaq Ñan, son áreas sísmicamente activas y las estructuras arquitectónicas podrían estar en peligro por los terremotos. Por lo que es necesario desarrollar esquemas de protección de riesgos para garantizar la seguridad de las personas y los recursos culturales. El 29 de noviembre de 2012 se creó un marco de política general para el Qhapaq Ñan con el documento de Estrategia de Gestión suscrito por 
los seis Estados Partes. Además de este acuerdo multinacional, los planes de gestión se desarrollarán a nivel regional para cada sección individual de la red de carreteras. También se recomendó que los Estados Partes, con el objetivo de asegurar la relación entre los diferentes sitios en términos de continuidad a pesar de su fragmentación, desarrollen mapas apropiados o un sistema GIS que ilustre las relaciones funcionales y sociales entre los diferentes componentes del Qhapaq Ñan.

\section{El programa de la Cátedra UNESCO de la Universidad de San Martín de Porres}

La Cátedra UNESCO Patrimonio Cultural y Turismo Sostenible de la Universidad de San Martín de Porres, ha elaborado un programa para los años 2018-20197, tendiente a desarrollar los objetivos planteados en la sustentación presentada a la UNESCO:

Contribuir al desarrollo sostenible del Perú, desde la Universidad, a través de la puesta en valor del patrimonio cultural, material e inmaterial, en los ámbitos locales, regionales y nacionales. Así como la promoción del turismo cultural sostenible y compatible con las normas y valores de las instituciones del patrimonio cultural establecidas en las diversas normas de las convenciones de la UNESCO. Empoderar a las poblaciones locales y regionales en sus factores identitarios, y promover la educación y el emprendimiento empresarial turístico a fin de preservar el patrimonio cultural. Tiene como objetivo formar profesionales y agentes empresariales del turismo cultural con una visión sostenible del turismo como actividad económica orientada a la preservación y conservación del patrimonio cultural de la Nación. El proyecto está dirigido a contribuir a la realización de los objetivos de patrimonio cultural y desarrollo sostenible contenidos en la Estrategia de Mediano plazo 2016-2021 de la UNESCO y los correspondientes a la agenda 2030. (USMP, 2017)

El cumplimiento de estos propósitos está basado en los siguientes componentes: La formación académica y profesional; La investigación; Editorial; y Proyección con la comunidad.

Para coadyuvar en la formación y capacitación de los estudiantes de los últimos ciclos de estudio se organizaron tres conferencias:

- Las convenciones UNESCO para la protección y salvaguarda del patrimonio cultural. Un marco global para el diseño de políticas públicas. Dictada por Alberto Martorell, presidente de ICOMOS-Perú, el 14 de mayo de 2018.

- La importancia de la Cultura y el Patrimonio para el cumplimiento de los Objetivos del Desarrollo Sostenible. Dictada por Enrique López-Hurtado, coordinador del Sector Cultura. UNESCO Lima, el 11 de junio de 2018.

- Hacia un nuevo análisis de la relación entre el patrimonio cultural y las comunidades. Dictada por Luis Elías Lumbreras, coordinador de Gestión y Descentralización del Proyecto Qhapaq Ñan. Sede Nacional del Ministerio de Cultura del Perú, el 15 de agosto de 2018.

7 Las actividades de la Cátedra UNESCO Patrimonio Cultural y Turismo Sostenible de la Universidad de San Martín de Porres, se difunde en su web: http:/l catedraunesco.usmp.edu.pel 
Así mismo, participamos en el conversatorio Cusco: Patrimonio Cultural y Turismo Sostenible, que se realizó en esta ciudad el 21 de mayo de 2018, organizado por la Cátedra Juan Meléndez, Centro de Estudios Superiores y de Investigación del Convento de Santo Domingo del Cusco, que desde hace tres años imparte cursos sobre turismo y patrimonio cultural dirigido a alumnos que ya han terminado la carrera de su especialidad; tienen una duración de dos semestres y es gratuito. A dicho conversatorio concurrió el Lic. Rogers Valencia Espinoza, titular del Ministerio de Comercio Exterior y Turismo (MINCETUR) presentando una conferencia titulada El patrimonio cultural y las políticas de estado hacia el 2021; y Sara Beatriz Guardia, Directora de la Cátedra Patrimonio Cultural y Turismo Sostenible de la USMP, que disertó sobre La evaluación que hace la UNESCO sobre su gestión en favor del patrimonio cultural y la sostenibilidad del turismo.

En el marco del componente editorial se publicarán dos libros:

- Perú: Patrimonio Cultural de la Humanidad. Manuel Rodríguez Cuadros. Embajador del Perú ante la UNESCO;

- Gastronomía Peruana. Patrimonio Cultural de la Humanidad. Sara Beatriz Guardia. Edición y compilación. Directora de la Cátedra UNESCO Patrimonio Cultural y Turismo Sostenible de la Universidad de San Martín de Porres.

También se están implementando acciones para establecer una relación de cooperación con la Secretaría de la UNESCO en la programación y ejecución de las actividades de la Cátedra, y se firmarán Convenios con Cátedras similares de América Latina con el objetivo de crear una Red cultural, y Convenios de Cooperación con gobiernos regionales y municipales.

\section{Seminario Internacional Patrimonio Cultural y Turismo Sostenible}

La Escuela Profesional de Turismo y Hotelería de la Universidad de San Martín de Porres y la Cátedra UNESCO Patrimonio Cultural y Turismo Sostenible de la USMP, han organizado para el 15, 16 y 17 de octubre el I Seminario Internacional Patrimonio Cultural y Turismo Sostenible, con el objetivo de analizar la situación del patrimonio cultural en el marco de la visión de UNESCO y de los contextos local, regional y global, así como, sus relaciones y vínculos con las comunidades locales y la actividad turística sostenible. Así mismo, resaltar la importancia de la labor de UNESCO a través de su red de agencias y programas en la conservación del patrimonio cultural del Perú, de la Región y del mundo; analizar el contexto actual y los riesgos que representa para el patrimonio cultural material e inmaterial; estudiar casos concretos y proponer alternativas para fortalecer los vínculos entre el patrimonio, el turismo y la comunidad; así como, formular propuestas que vinculen la conservación del patrimonio cultural y el desarrollo de un turismo sostenible.

\section{Revista Turismo y Patrimonio}

La Revista Turismo y Patrimonio del Instituto de Investigación de la Escuela Profesional de Turismo y Hotelería de la Universidad de San Martín de Porres está orientada a exponer a la comunidad científica y académica, las diferentes miradas, posturas y resultados sobre investigaciones vinculadas al patrimonio cultural 
y al turismo. La Revista contribuye así a la consolidación del turismo como objeto complejo de estudio científico, y a la profundización y divulgación del patrimonio como elemento central para las sociedades y su desarrollo.

Los artículos que conforman el $\mathrm{N}^{\circ} 12$ de la Revista versarán sobre temas relacionados con la Cátedra UNESCO, la Conservación del Patrimonio Cultural y el Desarrollo Sostenible.

Así mismo, se están implementando acciones para establecer una relación de cooperación con la Secretaría de la UNESCO en la programación y ejecución de las actividades de la Cátedra, y se firmarán convenios con cátedras similares de América Latina con el objetivo de crear una red cultural, y convenios de cooperación con gobiernos regionales y municipales.

\section{Referencias}

DeBrine, P. (2016). Interpretación del patrimonio para el futuro de Europa.

De Caro, S. (2014). Gestión del patrimonio mundial cultural. Manual de referencia. París: UNESCO, ICCROM, ICOMOS, UICN.

Centro del Patrimonio Mundial. (2009). Documento del Comité del Patrimonio Mundial con la sustentación de los criterios con los que se afirmó el valor universal excepcional de la Ciudad Sagrada de Caral-Supe y su inscripción en la Lista del Patrimonio Mundial.

Centro del Patrimonio Mundial. (junio, 2011). Declaración retrospectiva de valor universal excepcional de la Zona arqueológica de Chan Chan. Decisión WHC-11/35.COM/8E, aprobada en la 35 Sesión del Comité del Patrimonio Mundial (París).

Centro del Patrimonio Mundial. (junio, 2013). Declaración de Valor Universal Excepcional de la Ciudad del Cusco, Decisión WHC-13/ 37.COM/8E, aprobada en la 37 Sesión del Comité del Patrimonio Mundial (Phnom Penh). Recuperado de http:// www.perubicentenario.pe:80/turismo/patrimonio_ciudad_cusco.html

Centro del Patrimonio Mundial. (junio, 2013a). Declaración retrospectiva de valor universal excepcional del Santuario histórico de Machu Picchu. Decisión WHC-13/37.COM/8E, aprobada en la 37 Sesión del Comité del Patrimonio Mundial (Phnom Penh).

Centro del Patrimonio Mundial. (junio, 2013b). Declaración retrospectiva de valor universal excepcional del sitio arqueológico de Chavín. Decisión WHC-13/37.COM/8E, aprobada en la 37 Sesión del Comité del Patrimonio Mundial (Phnom Penh).

Centro del Patrimonio Mundial. (junio, 2013c). Declaración retrospectiva de valor universal excepcional del Centro Histórico de Lima. Decisión WHC-13/37.COM/8E, aprobada en la 37 Sesión del Comité del Patrimonio Mundial (Phnom Penh).

Centro del Patrimonio Mundial. (2014). Documento del Comité del Patrimonio Mundial con la sustentación de los criterios con los que se otorgó el Valor Universal Excepcional de Qhapaq Ñan y su inscripción en la Lista del Patrimonio Mundial.

Centro del Patrimonio Mundial. (julio, 2015). Declaración retrospectiva de valor universal excepcional del Parque Nacional Huascarán, Decisión WHC-15/39.COM/8E, aprobada en la 39 Sesión del Comité del Patrimonio Mundial (Bonn).

Centro del Patrimonio Mundial. (julio, 2015a). Declaración retrospectiva de valor universal excepcional del Parque Nacional Manu, Decisión WHC-15/39.COM/8E, aprobada en la 39 Sesión del Comité del Patrimonio Mundial (Bonn).

Centro del Patrimonio Mundial. (julio, 2015b). La declaración retrospectiva de valor universal excepcional del Parque Nacional Río Abiseo, Decisión WHC-15/39.COM/8E, aprobada en la 39 Sesión del Comité del Patrimonio Mundial (Bonn).

Centro del Patrimonio Mundial. (julio, 2015c). Declaración retrospectiva de valor universal excepcional de las Líneas y Geoglifos de Nazca y Palpa, Decisión WHC-15/39.COM/8E, aprobada en la 39 Sesión del Comité del Patrimonio Mundial (Bonn).

Centro del Patrimonio Mundial. (julio, 2015d). Declaración retrospectiva de valor universal excepcional del Centro Histórico de Arequipa, Decisión WHC-15/39.COM/8E, aprobada en la 39 Sesión del Comité del Patrimonio Mundial (Bonn).

ICOMOS. (27 de noviembre - 2 de diciembre, 2011). El patrimonio, motor del desarrollo (17ª Asamblea General y Simposio Científico). ICOMOS News, 18(1), 9. 
MONDIACULT. (1982). Conferencia Mundial sobre Las Políticas Culturales. Recuperado de http://www.unesco.org/new/es/mexico/ work-areas/culture/

Pedersen, A. (2005). Gestión del turismo en sitios del Patrimonio Mundial: Manual práctico para administradores de sitios del Patrimonio Mundial. París: UNESCO.

Rodríguez, M. (6-8 noviembre, 2017). La preservación y protección del patrimonio cultural del Perú en el marco de la Convención del Patrimonio Mundial (Seminario Internacional Patrimonio Cultural y Turismo Sostenible). Lima: USMP.

UNESCO. (1972). Convención sobre la Protección del Patrimonio Mundial Cultural y Natural 1972. Recuperado de http:// portal.unesco.org/es/ev.php-URL_ID=13055\&URL_DO=DO_TOPIC\&URL_SECTION=201.html

UNESCO, World Heritage Centre - WHC. (2008). Directrices Prácticas para la Aplicación de la Convención del Patrimonio Mundial. Paris. Recuperado de http://whc.unesco.org/archive/opguide08-es.pdf

UNESCO, ICCROM, ICOMOS, \& UICN. (2014). Gestión del patrimonio mundial natural. Manual de referencia.

Universidad de San Martín de Porres - USMP. (2017). Las actividades de la Cátedra UNESCO Patrimonio Cultural y Turismo Sostenible de la Universidad de San Martin de Porres. Recuperado de http://catedraunesco.usmp.edu.pe/

\footnotetext{
Sara Beatriz Guardia

Directora de la Cátedra UNESCO Patrimonio Cultural y Turismo Sostenible de la Universidad de San Martín de Porres

sarabeatriz.guardia@gmail.com
} 